\title{
A Penile Implant: Embodying Medical Technology
}

\author{
Jeffrey E. Nash \\ Missouri State University, USA
}

DOI: http://dx.doi.org/10.18778/1733-8077.17.2.05

Keywords:

Penile Implant;

Habitus;

Embodiment;

Looking Glass

Body

\begin{abstract}
This article situates the experiences of having penile implant surgery between medical interventions and privately understood meanings and practices. Using my own experiences, supplemented with information from online sources, I document the changes that occur in the meanings and the practices that implant surgery enables. My analysis derives from the concepts of habitus and the looking glass body, and it begins with a diagnosis of impotence and moves through the various considerations that lead to surgery and its aftermaths. I suggest that understanding how medical technology interacts with everyday meanings contributes to a wider application of the concept of habitus while expanding a symbolic interactionist perspective of the body.
\end{abstract}

Jeffrey E. Nash is a Professor Emeritus (Missouri State University) and former chair of the Department of Sociology and Anthropology at the University of Arkansas at Little Rock. He also served as a Professor of Sociology at Macalester College, St. Paul, Minnesota. He is the author of Deafness in Society with Anedith Nash, The Meanings of Social Interaction with James Calonico and he co-edited with Paul Higgins two editions of Understanding Deafness Socially. He has articles and book chapters on a wide range of topics, from bulldogs to barbershop singing. With Charles Edgley, he is currently the co-editor of the Journal of Contemporary Ethnography.

email address: jeffreyenash@gmail.com or jenash@ualr.edu

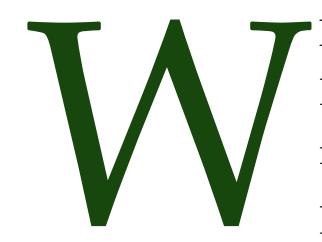

hile research on embodiment relates various ways that people imagine their bodies and their parts (Waskul and Vannini 2006; Allen-Collinson and Owton 2015), fewer studies exist of the social penis, that is, of the imputed meanings and cultural contexts in which the penis is displayed and understood. Some feminist scholars consider the penis to identify the "mechanisms of effacement by which the specificity of the physical penis is obscured by a phallic ideal" (Stephens 2007:85). By challenging phallocentric assumptions that underlie popular portrayals of the penis, feminists suggest that new meanings and relationships are possible. In other words, ideals about the po- 
tency of the penis are said to obscure the realities of it. Apparently, a close analysis is necessary to separate myth from reality.

In contemporary society, taboos against displaying and discussing "private" body parts have lessened. Consider such popular literature as The Little Book of Big Breasts and The Little Book of Butts (Hansen 2012; 2013). Most pointedly, Dodsworth's (2017) book, Manhood: The Bare Reality, displays photographs of 100 penises, pictures accompanied by personal narratives that the men tell about themselves and their penises. These men relate the impact of early experiences, trauma and illness, anxieties, and even pride about how they think and feel about their penises. While her book intentionally eschews any theoretical analysis, the narratives accompanying each picture reveal the emotional connections that men have with this particular organ. In another book, Paley (2000) covers anatomy, preferences in size and shape among men and women, and the roles that the penis plays in popular culture and art. And, Miller (1995) offers a brief history of the penis in sports, fashion, and literature, emphasizing the role this organ plays in defining masculinity.

Underrepresented in all this literature is a symbolic interactionist analysis of the social penis. However, the notion that body parts take on meanings that are functionally related to core and peripheral values of a culture and practices of a society is commonplace in anthropology. For instance, early ethnological studies of penis sheaths suggest that this particular aspect of a society's material culture reveals functional interdependencies among institutions. The sheath may actually promote modesty and enable its wearer to control any spontaneity of the penis, such as an erection (Ucko 1969).
Body parts have undergone analytic scrutiny. For example, Hoffmann-Riem (1994) relates in detail her experiences, emotions, and consequences in her relationships with others due to losing her eye to cancer surgery. And, as Atkinson (2006) shows, men may resort to surgery to preserve or reinforce meanings of masculinity, and with the advance of surgical technology, repairs of and improvements upon body parts can be spectacular successes. For example, the re-attachment of a severed penis was recently accomplished by a surgical team in India in 2016. Also, the surgical practices developed for penile implants (PIs) have been applied to constructing penises for transgendered individuals (Rooker et al. 2019). This application is a medical means of reaffirming gender identity.

In her research with women who elected to have female genital cosmetic surgery, de Andrade (2010) draws out the connection between the motivations of women and market-driven influences. She points to norms and images widely distributed through mass media that influence women's decisions to have such surgery. She also discusses ethical problems physicians face as they deal with possible ways to alter bodies.

Atkinson's (2006) study of men who have had facial surgery documents how, in an age of gender precarity, men privately and silently manage what they perceive as their shortfalls in meeting ideals of masculine appearance, while still achieving a modicum of control over it. While common supplements to the body such as glasses require less interactional work than surgical interventions, it appears that any altering of the biological body may call into question the social body. Ideals of appearance and medical procedures to achieve those ideals are conflated in the social meanings of the body. 
Medical interventions often alter the body, sometimes permanently. For instance, Manderson and Stirling (2007) depict how women refer to the site of the mastectomy, and they examine the shifts in perspective that are indexed in the way women talk about this absent body part. Women may objectify the scar by referring to "the breast" instead of "my breast," or even tattooing the scar to transform the absent breast into a part of the body.

Friedman (2001) documents using mythology, historical events, and changes in medical knowledge and practices how the relationship between man and his penis is often the key to a deep comprehension of epochs. Moving from ancient civilizations through changing conceptions of man and his penis, he identifies distinctive eras of the penis, from its roles in myths of the creation, through its demonization (the demon rod), its use to subjugate black men (the measuring stick), its role in psychoanalytic theories of nearly everything (the cigar), to the way scientific knowledge (both invalid and valid) changes the penis and its man. Friedman suggests that the penis is more than an organ: it is an idea that changes with history, as do all ideas of the body. However, at least in Western culture, understanding changes in the meanings of the penis can further understanding of culture in general.

According to Friedman, underlying meanings can be traced, however, to an ambiguous relationship between the man and his organ, a relationship that Friedman sees challenged by what he calls the erection industry (the industry built around the use of drugs, products, and procedures to enable an erection). In this article, I explore the aspects of the relationship between men and their organs by describing the changes that medicalization affects in awareness and practice after a penile implant.

\section{Private Parts}

I use Bourdieu's concept of habitus to specify an aspect of what Weinberg and Williams (2010) call the looking glass body. They employ the concept of looking glass body in their study of the meanings of the naked body as related to sexual performance. I suggest that conceptualizing the body as social and consisting of at least a private parts habitus allows a symbolic interactionist perspective of the consequences of alterations of the penis.

I relate how PI surgery modifies and integrates into the looking glass body. As a device of this body, habitus refers to the physical embodiment of cultural capital, to the deeply ingrained habits, skills, and dispositions that we have acquired through life experiences in a particular social and cultural nexus. Habitus allows for and enables the navigation of social worlds. And, since it exists in a reciprocal relationship with "objective" social structure, understanding the particular aspects of a given habitus and its functions permits extrapolation to structures and back to situations. The concept has been applied to an astonishing array of subjects from cars (Sheller 2007), barbershop singers (Nash 2012), linguistic practices (Jones 2001), and even bathroom habits (Weinberg and Williams 2005).

A private parts habitus refers to meaning and practices associated with intimate anatomy that accumulate over one's lifetime, and that reflect sexual history and eccentricities. Of course, there can be variation within this habitus. For example, while Dodsworth's (2017) book centers on the penis, its main message ranges outward to stories of sexual conquest, failures, embarrassment, and bragging rights. Clearly, men develop an understanding of what this part of their self means and what they 
can and cannot do with it. Ambiguity and/or crisis in this habitus is implicated in decisions to have PI surgery.

A private parts habitus is embodied in institutional meanings and societal structures at the macro lev$\mathrm{el}$ and in a concept of the body at the micro. From childhood, boys learn to conceal their penis, display it in situationally appropriate ways, and most importantly, to treat the penis as private. These social practices and the meanings that one gives the penis can have medical meanings, or as Friedman suggests, a crisis of the penis and medical response to this crisis has lead to the erection industry. A patient, hence, has a well established private parts habitus that remains largely tacit whenever he visits a urologist, for example. Impotency creates a crisis within the private parts habitus. What follows are narratives of that crisis that illustrate the linkages among meanings and practices.

\section{Medicalizing the Penis}

A symbolic interactionist perspective can augment the medical model. By conceptualizing the habitus as one of many cognitive and emotional devices for creating what Weinberg and Williams (2010) call a looking glass body, by which we mean the interpretations and emotional reaction that an actor makes of their body within the imaginations of the judgment of others.

The medical model begins when a patient seeks a physician's help for his impotence. The physician typically pays little attention to the patient's private parts habitus. I recall being asked no questions about how I think about my penis. After diagnosis, the physician describes possible causes, but they move quickly to detailed accounts of remedies. By overlaying the looking glass body and its device, the private parts habitus, on the experience of having PI, I intend to understand the personal and social consequences of PI surgery. Whereas the medical model emphasizes outcomes, the symbolic interactionist model highlights meanings.

All manner of human fragilities, from drug abuse to deformities, have been transformed into medical problems that purportedly have solutions that are devoid of stigma and thoroughly normalized. Such is the case with male impotency. Impotency, in everyday life meanings, goes beyond the dysfunction of an organ to the man himself. When we say a man is impotent, we degrade him, and, as the word suggests, we see him as having lost power in some sense. Men who experience impotency often experience challenges to their self-esteem and sense of worth. Impotency, we might say, shatters the looking glass body. Impotency may become a stigma, but since it is not public, it discredits only in private or intimate interactions. Goffman (1963) might have called it a stealth stigma had he analyzed impotency since it is invisible in public interaction. Of course, as a cause of more visible manifestations, such as depression or irascibility, impotence, if uncovered in interaction, could be a stigma. Some people who have used online dating services for senior adults report that potential partners may discuss sexual activity. Thus, neutralizing stigma becomes necessary for continuing the relationship (personal communication).

The condition of impotency, especially in older men, has ramifications that affect self-concept, and, certainly, relationships not only with intimate partners but with others as well. A study of the expectations men with erectile dysfunction (ED) have before treatment shows that relationships 
with partners are an important consideration in choosing a treatment and that expected outcomes include increased quality of life (Henninger et al. 2015).

Therefore, impotence, once seen as a character weakness or even the consequence of immoral and lascivious habits, is discussed in the medical model in anatomical and metric terms, and medical technological interventions are the main resources for restoration, normalization, and stigmatic neutralization (Friedman 2001).

The vast literature on the medical model covers an array of illnesses and dysfunctions (Conrad 1992; 2005; Conrad and Schneider 1992), but there are few detailed narratives about the penis. Critiques of the medical model do exist: for instance, Tiefer (1994) refers to phallocentrism (the assumption that it is possible to achieve the perfect erection through medical intervention) as detrimental to appreciating the full range of degrees of erections and the accommodation that partners make to these variations. His critique implies that couples can have pleasure with a partially erect penis. However, correctives such as his to the medical model are rare and remain outside the scope of the medical model of the penis.

The medical model begins with the physician's assumption that the patient had at one time a "normal" sex life. Whatever that life might be is irrelevant since the physician uses this assumption as a starting point for diagnosis. Usually, this amounts to a brief account of the cause of impotency. The causes of impotence are richly depicted, running the gamut from traumas such as automobile accidents, sports injuries, to diseases of various kinds, most typically those that restrict the flow of blood to the penis. However, regardless of the cause, attention shifts quickly to remedies, glossing over the details of a man's private parts habitus.

Knowledge and description of the remedies for impotence is rich and detailed in the medical model. These remedies vary from pharmaceutical to elaborate accounts of surgery. In the case of PI surgery, one can find technical professional descriptions of the surgical procedures, a video showing an actual operation, and one demonstrating in a manner devoid of eroticism how to use the penile pump. Most of these websites are sponsored by physicians or businesses that manufacture the devices.

PIs have been available as a treatment for ED since the 1970s. There are several types of implants, but the most popular use a reservoir implanted in the abdomen, a squeezable rubber pump inserted in the scrotum, and inflatable tubes implanted on either side of the penis. While no accurate count exists for the number of men in the US who have an implant, PI is a common treatment for men for whom pharmaceutical treatments have proven ineffective, and for those with ED as a condition resulting from some health issue. Cases of ED are increasing in the US, with an estimated 30 million men with the condition. There are several causes for ED, some of them linked to obesity and arterial diseases, others to diabetic conditions or trauma. For example, some causes of ED include Peyronie's disease, side effects of prostate surgery, and even reaction to medications.

With the introduction of ED medicines such as Viagra and Cialis, the percentage of patients electing to have the surgery has declined (Smart, CNN, 
June 23, 2015'1). Still, the procedure is considered one of the most "successful" of all operations. Surveys have reported impressively high patient satisfaction with the outcome of the surgery. Generally, a consistent $90 \%$ of patients and their partners report they are satisfied or happy with their implants; that they have resumed intercourse within weeks of the surgery; and that they are largely satisfied with the surgical result (Bettocchi et al. 2009; Carvalheira, Santana, and Pereira 2015). These surveys gloss over the details that constitute satisfaction and leave unexplored the interactional impact that a technological intervention on the genitals can have.

I relate aspects of my account of male impotence and those of men who post comments at websites devoted to such discussions to supplement and enrich the medical model with lived-through meanings. At the forefront of the analysis is the sense that men make of the "problem," and how a private parts habitus is modified and maintained. While the medical model minimizes the patient's private parts habitus, emphasizing technical and anatomical features of the penis, a symbolic interactionist narrative considers the significance of the surgery for the nature and character of the habitus, even though the medical narrative frames the overall process.

\section{My Method}

My experience of ED and my decision to have a PI provided an opportunity to describe the private parts habitus in general and for myself, specifically (see: Riemer 1977). After several visits to my family physician, I learned the reason for my ED was prob-

1 See: https://edition.cnn.com/2015/06/23/health/penile-implants-erectile-dysfunction/index.html. Retrieved February 14, 2021. ably circulatory-plaque somewhere in the system. After a negative carotid artery scan by my general practitioner, I was referred to a urologist who specialized in PI surgery, who encouraged me to read and think about having the procedure done. I began to ponder my private parts habitus and to imagine the accommodations my wife and I would have to make to the implant. She and I had long talks about the operation, and some of those discussions are referred to in the text. I also visited the website, Frank Talk (https://www.franktalk.org), where I searched discussion forums and active topics for posts that could serve as evidence for my analysis.

I offer here an account of selected aspects of my experience of having an implant. This analysis rests on my experience with this transformative process, but it pushes observational opportunities to a degree that collapses the distance between the observer and observed, that is, I observe myself. However, as Becker (2017) writes, using one's experiences as evidence for sociological ideas is not new. Roth (1963) turned his tuberculosis into an opportunity to test sociological concepts. Roy (1952) used his job in a machine shop to create evidence for generalizations about how workers organized their time on the line.

While my method is primarily participatory, similar to such works as Murphy's (1987) The Body Silent (1987), I also follow what Anderson (2006) calls analytic auto-ethnography, which emphasizes that personal experiences are grounded in a sense of membership (for me, men with PIs). In analytic auto-ethnography, one's presence in the text is committed to situating one's experiences within an abstract set of concepts that permit sociological insights. Hence, as I recall experiences, look at notes, and reconstruct events, I do so both as a patient and sociologist. 


\section{How the Transformation Starts}

The decision to have implant surgery follows a process. While I identify this process from my experience, other men describe it similarly. First, there is a disruption or breach in the private parts habitus resulting from a variety of sources. Then comes a period, usually fairly lengthy, of various remedies for ED. These remedies, while successful for many, do not work for all men. In fact, the "success" rates for ED drugs are often greatly exaggerated in popular understandings. As the following quote suggests, while there are many causes of impotency and many remedies tried, for a man who decides to have PI surgery, there develops an awareness that pharmaceutical remedies are not working and the hope of easy restoration disappears. At some point, such men have a "come to Jesus" moment, that is, face the biological reality that one will never again have a "natural erection." An anonymous man in a chat room put it this way:

I am 59 years old and have had ED for about 6 years. Probably a side effect of my diabetes type II. Have tried the pills and that was great for a few years but kind of expensive. After that it was pump [a reference to a mechanical device] which worked but was damn trouble having to stop the flow of love making to pump up the penis. Tried the shots but I could not get past sticking my penis with a needle. It is just not natural and I did not get a real good erection and now take Cialis $5 \mathrm{mg}$ daily and use the pump. it works but there had to be something out there that was better. I had a come to Jesus meeting with my Uro and we discussed all the pros and cons of the implants. Based on his information and talking to the guy on Frank TALK, I have decided to go ahead and get the implant this fall. that in a nutshell is my story. [Frank Talk, 2016 (original spelling)]

\section{The Medical Examination}

The pre-operative examinations for PI surgery bear similarities to the emotional management and de-eroticization that Emerson (1970) describes in her article on observations of such examinations. Just as doctors and nurses follow routines of action and speech that are aimed to take any sexual intent or meaning out of a woman's gynecological examination, so do the doctors and nurses who specialize in a man's PI surgery and treatment.

For example, after a discussion of the way a penile pump works and how mechanisms of ejaculation remain unaffected, a lengthy warning about the percentages of cases involving infections, and answers to questions about the effects on the glans (will it engorge post PI operation?), the doctor looks solemnly at me and says, "Now, let's look IN your penis." After the shock of the "IN," he proceeds to do just that. The examination includes an internal manual check of the prostate and a look for abnormalities; and, after the doctor's decision that surgery is a possibility, there is a consultation between doctor and patient. Sometimes the patient requests time to "think about it." Finally, a mutual doctor-patient agreement is made and a date for surgery is set. In my examinations, my wife accompanied me and took part in all discussions.

\section{The Surgery}

The experience of surgery as a social form remains a relatively unexplored domain. Millions of people around the world have "had surgery." In the US, it is a highly routinized experience with pre-operative procedures that include the creation of a "case" and "charts," all of which can be understood as the construction of a medical entity, that is, a person 
becoming socialized as a patient (cf. Parsons 1951; Arluke, Kennedy, and Kessler 1979; Perry 2011). Surgery transforms the status and identity that one brings to the hospital, and thereby one loses most, if not all, of their previous social identities. A patient may also have high social status, for instance, be a physician or another kind of "very important person," but while these statuses may affect when and where surgery is scheduled and whether a particular surgeon performs the procedure and other perks associated with high status, "surgery" as a social form governs the experience. Of course, surgeries vary from saving life to cosmetic alterations of facial features, and considerations such as the ethnicity, race, or gender of the patient do influence, sometimes dramatically, the social contexts that accompany undergoing a surgery. One such context can be the economic impact of the procedure, but in my case, because of being age 74, Medicare covered it, which saved quite a bit of distress, given that the cost of inpatient operation with overnight recovery is about $\$ 50,000$ at a state medical center and more at private facilities.

In the case of an alteration of male private parts, the experience of surgery is not distinctive from other forms of surgery. The check-in is the same, as with any surgery that requires an overnight stay, protocols govern virtually every step leading to the surgery itself. I point out the ordinary nature of the preliminaries for having PI surgery to contrast the extraordinary effect it has on altering the "private parts" habitus.

\section{Out, Damned Catheter}

After the operation, coming out of recovery, and upon awaking from the night in the hospital with all that it entails (blood pressure checks, sleep in- terruptions from nurses), I saw two young women standing at my bedside. One of them cheerfully announced that they were there to remove the catheter, which had been in place since the surgery. That they did, grabbing my penis with one hand and pulling the catheter out with the other. Such pain I have rarely experienced!

I was able to walk a little and joke with my wife about my hopefully temporary predicament, but the swelling of my scrotum was nothing short of specular. When I asked about whether this was normal, a nurse claimed that she had seen them the size of a basketball. Some patients, she added, swell very little. I concluded that my set of black and grapefruit-sized balls were somewhere near average, but I was only slightly relieved.

Furthermore, not disclosed in the preliminaries leading to surgery, was that the procedure included a deliberate puncture of my huge blackened scrotum, which for several days bled a steady drip, soaking several pads a day. Of course, this drain hole was there to minimize swelling. Still, keeping the swelling under control required ice packs and soaks in the bathtub. These soaks in the bath were particularly memorable since the water was often red with blood. At this point, thoughts about sexual activity were remote, and I hoped for at least a return to a normal scrotum. With a bruised penis and a huge leaking scrotum, my private parts habitus had been severely transformed.

Over the next few weeks, my penis and scrotum slowly returned to normal sizes and colors. My private parts habitus slowly re-emerged, as I recognized the shape and feel of my "normal" penis, that is, according to my pre-operative private parts habitus. Several months later, I had more or less 
fully recovered. Later, my family care physician asked how the surgery went, and I showed him a picture of my swollen, discolored scrotum. His eyes widened, and he said, "I haven't seen anything like that since I worked on a cadaver in medical school."

Total recovery from the surgery took weeks and required serious rethinking about what my scrotum should feel like. Since the pump mechanism in it now has become a "third ball," the habitus must adjust. Within two to three weeks after surgery, it is possible to pump up the penis. However, since lingering swelling can last several months, the very thought of squeezing the bulb to achieve an erection does little to evoke erotic images. Also, since the entire scrotum has been recently bruised, pumping it up can turn the scrotum blue. Since patients sometimes have trouble learning how to pump, return trips to the doctor's office may be necessary.

As time passes and swelling goes down, normal skin tone appears and thoughts of a resumed sex life, the primary reason for the ordeal, return. Penetration after surgery can be thrilling and quite satisfactory for both partners. During foreplay, for me, there were moments of doubt as to whether the penis was "hard" enough to penetrate, and whether or not I had mastered the technique of achieving full inflation (erection). For my wife and I, the first try was successful and joyous, as we laughed and welcomed the return of our previous sex life.

The return of the "rod," as Friedman (2001) might say, can be a marker for the re-established habitus. Eventually, perhaps six months post-surgery, the pump becomes a "natural" part of one's anatomy, and the outline of the pump and its deflation valve can be felt. The bulb can be moved around within the scrotum and squeezing it to inflate the penis no longer made me squeamish. In fact, so does squeezing the penis become "normal," as does the low squishing sound produced by fluid passing from tubes in the penis, back to the reservoir.

\section{De-Erotic Techniques}

A private parts habitus enables various interpretations of touching one's genitalia, from scratching and masturbation to the erotic. And, whenever a medical procedure requires touching some part of the genitalia, as Emerson (1970) documented, it entails de-eroticizing techniques to convert private meanings into medical. Some of these techniques include: settings (medical offices, standardized decorum, medical equipment, a sterile and officious ambiance), use of the patient's surname, uniform surgical dress for the medical staff, and a gown for the patient.

Controlling gaze is another technique used by medical staff. This involves not only minimal eye contact, but also facial expressions and body language that neutralize any possible erotic meanings. Touches are brief, glove-covered, and mechanical. Soon after my return home from surgery, I was having difficulty inflating the tubes to achieve an erection. Inflating or pumping up entails grasping the bulb that is now inside the scrotum and squeezing it hard. Since that entire area is sensitive for weeks after the surgery and since squeezing the bulb pinches the skin of the scrotum, learning to accomplish an erection requires a little practice. The bulb is slippery and the bulb sometimes "airlocks," which means it is necessary to squeeze harder to move the air bubble out of the bulb. I had to return to the doctor's office twice to ensure that 
the mechanism was operating properly. Both times I was assigned a female nurse who had a reputation of being skilled at helping patients learn "pumping up." She entered the examination room, requested that I drop my pants (no gown this time), then quickly and clinically, without looking me in the eye, seized the bulb and, with a deft forefinger to the thumb, squeezed to demonstrate the proper technique. I was impressed with her skill.

The doctor then entered the room and suggested that when I become comfortable with the inflating technique, it could become part of foreplay. He and the nurse were offering advice about how to reconfigure a private parts habitus so that the mechanical procedure can replace or substitute for the organic arousal stage of foreplay. But, I learned that before that can happen, the technique must become effortless, and distracting "airlocks" must be cleared well before foreplay starts, so for my wife and me, it never became part of foreplay.

Throughout these post-operative visits to the doctor's office, the use of medical jargon and references to studies and results from others' experiences also function to de-eroticize the meanings associated with discussing private parts. By allusion, however, common-sense everyday knowledge was acknowledged by the doctor; for example, he referred to variations in penis size among patients and pointed out that the devices are designed to accommodate the size. Needless to say, such discussions concerning the pros and cons of the different types of PI devices (Coloplast Titan, AMS 700, non-inflatable, AMS Ambicor), the results of patients' satisfaction surveys, peppered with medical terms such as glans and prostheses, can be quite effective in de-eroticizing any conversation about one's private parts.

\section{Reconfiguring the Private Parts Habitus}

The meanings carried within habitus have relative permanency, particularly since their enactment reinforces and turns social structures into useful interactive devices (Wacquant 2016:70). As the term itself suggests, habits and deeply rooted cultural tropes, reinforced by everyday applications, result in firmly established ways of making sense of male genitalia. Describing the ways that accommodation takes place illustrates both the flexibility and the permanence of core meanings, and the habitus is so persistent that it allows the cultural tropes to continue. For example, if a man were particularly proud of the length of his penis, and penis length is a cultural trope in mass entertainment and common-sense knowledge, he must re-interpret what the loss of length means.

Irrevocable changes in the size and shape of the penis result from PI surgery. Both girth and length of the penis are, post PI, determined by the tubes and what is left of the corpus cavernosum, columns of tissue running along the sides of the penis, and the corpus spongiosum, a column of sponge-like tissue running along the front of the penis and ending at the glans. Since the anatomy of the penis has been altered and these components are central to a "natural" erection, there can be no "natural" erection, and the girth of the penis is slightly smaller. Of course, "slightly less" in an objective sense can be "much less" in the private parts habitus. Many men seem to be bothered by this effect of the PI, as this is often mentioned in online chat groups.

Most men consider these losses to be more than compensated by restored function. After recovery from surgery, most men report that they regain that "old feeling," especially after an ejaculation. 
During sexual arousal, they report having phantom sensations of a natural erection. This is partly the result of the glans enlarging and of the neurological linkage between the brain and penis that triggers a natural erection. Whatever the "natural" connection, in the reformed habitus, these sensations become "natural" in the sense that they form a reconstructed habitus.

In addition to the altered feeling of arousal, there are other changes to the anatomy of the penis that require interpretation. A flaccid penis becomes a deflated penis, and an erect penis no longer stands upright, but sticks straight out from the body. The feeling of pumping up replaces spontaneous arousal, and there is the feeling of having a "hybrid dick," since the flexible plastic tubes on either side of the shaft, when deflated, feel as if they are kinked like a garden hose. According to online sources, partners, including mine, mention the altered feel of the shaft (Frank Talk 2018). They report learning to accept "new" sensations as "ordinary," when caressing and stimulating the penis. One modification mentioned by a partner had to do with recognizing when her partner was "truly" aroused. In "normal" foreplay, the penis shaft becomes tumescent to a degree that is obvious to the person stimulating it. However, after a PI, the shaft is non-responsive to stimulation; hence, a partner must rely on communicative cues and sensing the slight enlargement of the glans. The period of adjustment to this change is typically short, though in some cases, it may become a problematic feature of the foreplay routine. In my search of the chat rooms, discussion boards, and literature, I saw no mention of the long-term effects of this modification of the penis.

Routinization plays a crucial role in normalizing the effects of the PI. Most men report that within a few months of the operation, after healing is complete, there is no sense of artificiality. Still, sitting and sleeping in certain positions, is a reminder that "it is industrial" down there: the bulb requires accommodation while crossing one's legs. In due time, the apparatus transforms into something natural and becomes "mine."

Also, problematic are public displays of the penis after PI. Whenever daily routines such as exercise at the gym, hunting trips, or other occasions requiring being undressed in front of other men, one must be sure that the penis is completely deflated to appear non-sexual. Since the penis can no longer shrink and daily movements, especially rigorous exercise, can cause some fluid to enter the shafts, resulting in a semi-erection, it is necessary to deflate it fairly regularly to avoid embarrassing situations.

In one particular case, an informant remarks, half-jokingly, that he is troubled that his "new" penis leans to the "right," which is contrary to his political inclinations. While this seems a trivial concern, it illustrates just some of the necessary changes required for the habitus to routinize and de-problematize the appearance of the penis.

Another aspect of public display involves deciding with whom to discuss having had the operation. Do you tell family members or friends about the PI surgery? I did tell some friends about it, one who had had PI surgery himself and another, a physician, both in presumed confidence, to avoid stigma. However, in the case of family members who knew I had had an operation, my wife and I referred to it as hernia surgery. In other words, I maintained my previous self-presentation through lying (cf. Sacks 1975). 


\section{The Looking Glass Penis}

Charles H. Cooley's (1922) concept of the looking glass self suggests that our images of ourselves are formed from our imagination of how we think and feel about how others think and feel about us. Weinberg and Williams (2010) apply the concept to how partners think and feel about their naked bodies during sex. They find that the looking glass body is directly related to more general assessments about the meanings of sex. For example, more positive images of one's body are associated with a greater variety of sexual activities, and among women, negative or self-critical attitudes about their nude bodies restrict sexual practices.

Whether a sex partner or a shower buddy notices, or cares to glance at the naked penis, the habitus is still affected. As indicated above, many changes must be refigured both literally and within the mind (cf. Mead 1934). Following Cooley (1922), here is a sketch of the looking glass penis:

My imagination of how I think my penis appears to others, both privately and publicly.

My imagination of how others evaluate its appearance.

My emotional reaction to that imagined evaluation.

To add a description to the concept of the looking glass penis, consider the matter of size. Research shows a variation in size and appearance of the penis (Veale et al. 2014). Furthermore, an "objective" study of how women think about penis size (Prause 2015) shows that women may vary in what they prefer in penis size, according to whether they imagine an encounter with one in a one-night stand or a long-term relationship. For example, the women in the sample of this study preferred a larger penis for a casual encounter and one only slightly larger than average for a long-term relationship.

In contrast to this "objective" reporting, consider what a man imagines his partner's view of the appearance of his penis to be. He may think of himself as small or large, and he may project this image onto his partner's view. The insight that interactionism contributes to such an understanding is that it is what the man thinks his partner thinks that shapes the private parts habitus. If a man imagines that others (intimate and public) see him as "large," he may be dissatisfied with the loss of both girth and length from PI surgery. Likewise, if he is "small," then the surgery may exacerbate the perspective of being small. If there are other irregularities in the penis or scrotum, the possible concerns become more complex.

When a man imagines how his appearance is evaluated by others, he may see the decrease in size as irrelevant, since his partner never mentions it. Also, he may limit exposure to the public by avoiding showering at the gym or managing his exposure through the use of a towel or robe. On the other hand, the tubes in the shaft of the penis prevent a fully flaccid penis and a man may imagine that he appears "larger" than he was preoperative. Hence, he may be even bolder or less reluctant to expose his "public" penis.

The emotional reaction to altered genitalia may range from "what do I care" to "you should be so lucky." Generally, survey data following PI surgery indicate that men are quite satisfied and quickly establish a "normal" private parts habitus (Carvalheira et al. 2015). In other words, the altered penis and the meanings of intimacy become 
normalized through routine and acceptance, even if imagined.

\section{When Technology Fails: Disembodiment}

Even a brief visit to chat rooms where PI surgery is discussed reveals that there are circumstances in which PI surgery might be considered a failure. These outcomes and the sense that men make of them are typically due to general poor health, problematic relationships with partners, or even a fatalistic stance towards aging. While these interpretations of the consequences of the surgery are fairly uncommon (less than 10\% of all PI surgery), they do reveal another way to make sense of the experiences.

I got my implant several years ago and have always had problems with it. Got an infection and had to have it removed and then re-implanted. My partner is not much interested in sex anymore, and frankly, if I have any more infections, I'll just get the thing out and forget about it. [Frank Talk, 2017 (original spelling)]

I have no information about how this man's partner thinks and feels about this situation. Our chat room friend, however, clearly has a fatalistic view of the whole matter. Emphatically, I agree that enduring PI surgery more than once with an unenthusiastic sex partner could well lead one to wish for dispensing altogether with the pain and the troublesome aspects of sexual relationships. However, even though the PI apparatus can be removed, the reconfiguration of the habitus has already happened, so PI surgery continues as a lingering influence on the habitus. In this case, I can imagine this man being reminded of the ordeal each time he touches or looks at his permanently limp penis.

\section{Conclusion}

Both medically and socially, PI surgery requires the patient to rethink what constitutes a normal penis. The normalization process outlined in this article traces the meanings of a penis through erectile dysfunction, testing for diagnostic purposes, medical remedial steps, the decision to have surgery, the experiences associated with surgery, and the subsequent modifications of his private parts habitus, as well as that of the looking glass body.

Bourdieu (1984) intended his concept of habitus to strengthen a theoretical understanding of the articulation between individual and society (Wacquant 2016). The depiction of a private parts habitus uncovers interrelationships among individual understandings of body parts and the embodiment of medical interventions. In the case of PI surgery, the individual (the patient) and society (modern evidence-based medicine) interact to rationalize medical intervention and normalize an altered aspect of the looking glass body.

The embodiment process described here may be prescient of other technological interventions such as bionic prosthetic legs and hands. The malleability of self-awareness and its accommodation to radical changes demonstrated in this analysis may extend to the merger of technology and biology. I suggest that understanding changes in the private parts habitus may contribute to understanding how technology and biology interact. In particular, the testimony of partners and the experiences related by men who have undergone the PI procedure demonstrate the resiliency of habitus and the flexibility of the looking glass body. 


\section{References}

Allen-Collinson, Jacquelyn and Helen Owton. 2015. "Intense Embodiment: Sense of Heat in Women's Running and Boxing." Body and Society 21(2):245-268.

Anderson, Leon. 2006. "Analytic Autoethnography." Journal of Contemporary Ethnography 35(4):373-395.

Arluke, Arnold, Louanne Kennedy, and Ronald C. Kessler. 1979. "Reexamining the Sick-Role Concept: An Empirical Assessment." Journal of Health and Social Behavior 20(1):30-36.

Atkinson, Michael. 2006. "Masks of Masculinity: Cosmetic Surgery and (Sur)Passing Strategies." Pp. 247-261 in Body/Embodiment: Symbolic Interaction and the Sociology of the Body, edited by P. Vannini and D. Waskul. Burlington, VT: Ashgate Publishing.

Becker, Howard S. 2017. Evidence. Chicago: University of Chicago Press.

Bettocchi, Arlo et al. 2009. "Patient and Partner Satisfaction after AMS Inflatable Penile Prosthesis Implant." Journal of Sexual Medicine 7:304-309.

Bourdieu, Pierre. 1984. Distinction: A Social Critique of the Judgement of Taste. London: Routledge.

Carvalheira, Ana, Rita Santana, and Nuno M. Pereira. 2015. "Why Are Men Satisfied or Dissatisfied with Penile Implants? A Mixed Method Study on Satisfaction with Penile Prosthesis Implantation." Journal of Sex Medicine 12:2474-2480.

Conrad, Peter. 1992. "Medicalization and Social Control." Annual Review of Sociology 18:209-232.

Conrad, Peter. 2005. "The Shifting Engines of Medicalization." Journal of Health and Social Behavior 46(1):3-14.

Conrad, Peter and Joseph Schneider. 1992. Deviance and Medicalization: From Badness to Sickness. Philadelphia: Temple University Press.

Cooley, Charles H. 1922. Human Nature and the Social Order. New York: Charles Scribner and Sons.

de Andrade, Daniela Dorneles. 2010. “On Norms and Bodies: Findings from Field Research on Cosmetic Surgery in Rio de Janeiro, Brazil." Reproductive Health Matters 18:74-83.
Dodsworth, Laura. 2017. Manhood: The Bare Reality. London: Pinter and Martin.

Emerson, Joan P. 1970. “Behavior in Private Places: Sustaining Definitions of Reality in Gynecological Examinations." Pp. 7497 in Recent Sociology No. 2, edited by H. P. Dreitzel. New York: The Macmillan Company.

Friedman, David M. 2001. A Mind of Its Own: A Cultural History of the Penis. New York: Free Press.

Goffman, Erving. 1963. Stigma: Notes on the Management of Spoiled Identity. New York: Simon and Schuster.

Hanson, Dian. 2012. The Little Book of Big Breasts. Cologne: Taschen.

Hanson, Dian. 2013. The Little Book of Butts. Cologne: Taschen.

Henninger, Silvia et al. 2015. “Treatment Expectations of Men with ED and Their Partners: An Exploratory Qualitative Study Based on Grounded Theory." International Journal of Impotence Research 27:167-172.

Hoffmann-Riem, Christa. 1994. "Losing a Symbolically Significant Part of the Body." Pp. 352-364 in Elementare Phänomene der Lebenssituation [Elementary Phenomena of the Life Situation], edited by W. Hoffmann-Riem, M. Pieper, and G. Riemann. Weinheim: Deutscher Studien Verlag.

Jones, Katharine W. 2001. “'I've Called'em Tom-ah-toes All My Life and I'm Not Going to Change!' Maintaining Linguistic Control over English Identity." Social Forces 79(3):1060-1094.

Manderson, Lenore and Lesley Stirling. 2007. "The Absent Breast: Speaking of the Mastectomied Body." Feminism and Psychology 17(1):75-92.

Mead, George H. 1934. Mind, Self, and Society. Chicago: University of Chicago Press.

Miller, Toby. 1995. “A Short History of the Penis.” Social Text 43:1-26.

Murphy, Robert. 1987. The Body Silent. New York: Norton.

Nash, Jeffrey E. 2012. "Ringing the Chord: Sentimentality and Nostalgia among Male Singers." Journal of Contemporary Ethnography 41:581-606. 
Paley, Maggie. 2000. The Book of the Penis. New York: Grove Press.

Parsons, Talcott. 1951. The Social System. Glencoe, IL: Free Press.

Perry, Brea L. 2011. "The Labeling Paradox: Stigma, the Sick Role, and Social Networks in Mental Illness." Journal of Health and Social Behavior 52:460-477.

Prause, Nicole et al. 2015. "Women's Preferences for Penis Size: A New Research Method Using Selection among 3D Models." PLOS One. Retrieved February 16, 2021 (https://journals.plos. org/plosone/article?id=10.1371/journal.pone.0133079).

Riemer, Jeffrey W. 1977. "Varieties of Opportunistic Research." Urban Life 5:467-477.

Rooker, Steven A. el al. 2019. “The Rise of the Neophallus: A Systematic Review of Penile Prosthetic Outcomes and Complications in Gender-Affirming Surgery." Journal of Sexual Medicine 16(5):661-672.

Roth, Julius A. 1963. Timetables. Indianapolis, IN: Bobbs-Merrill.

Roy, Donald. 1952. "Quota Restriction and Goldbricking in a Machine Shop." American Journal of Sociology 57:425-442.

Sacks, Harvey. 1975. “Everyone Has to Lie.” Pp. 57-80 in Socio-Cultural Dimensions of Language Use, edited by B. Blount and M. Sanches. New York: Academic Press.
Sheller, Mimi. 2007. "Bodies, Cybercars, and the Mundane Incorporation of Automated Mobilities." Social and Cultural Geography 8(2):175-197.

Stephens, Elizabeth. 2007. “The Spectacularized Penis." Men and Masculinities 10:85-98.

Tiefer, Leonore. 1994. "The Medicalization of Impotence: Normalizing Phallocentrism." Gender and Society 8:363-377.

Ucko, Peter L. 1969. Penis Sheaths: A Comparative Study. London: Royal Anthropological Institute of Great Britain and Ireland.

Veale, David et al. 2014. “Am I Normal? A Systematic Review and Construction of Nomograms for Flaccid and Erect Penis Length and Circumference in up to 15,521 Men." Sexual Medicine 115:978-986.

Wacquant, Loïc. 2016. "A Concise Genealogy and Anatomy of Habitus." The Sociological Review 64:64-72.

Waskul, Dennis and Phillip Vannini, eds. 2006. Body/Embodiment: Symbolic Interaction and the Sociology of the Body. Burlington, VT: Ashgate Publishing.

Weinberg, Martin S. and Colin J. Williams. 2005. “Fecal Matters: Habitus, Embodiment and Deviance." Social Problems 52(3):315-336.

Weinberg, Martin S. and Colin J. Williams. 2010. “Bare Bodies: Nudity, Gender, and the Looking Glass Body." Sociological Forum 25:47-67.

\section{Citation}

Nash, Jeffrey E. 2021. “A Penile Implant: Embodying Medical Technology.” Qualitative Sociology Review 17(2):88-102. Retrieved Month, Year (http://www.qualitativesociologyreview.org/ENG/archive_eng.php). DOI: http://dx.doi.org/10.18778/17338077.17.2.05 